\title{
Photobleaching characteristics of traditional Japanese paper in a museum environment
}

\author{
Kosuke Nakagoshi, Kunio Yoshizumi*
}

Kyoritsu Women's University, Tokyo, Japan;

*Corresponding Author: yoshizumi@kyoritsu-wu.ac.jp

Received 16 September 2011; revised 22 October 2011; accepted October 29, 2011.

\begin{abstract}
Photobleaching of aged traditional Japanese paper that has been thermally yellowed during storage for 200 years was examined from the standpoint of accumulated light radiation dosage in a museum environment. The light intensity was evaluated using a blue wool reference of the Japan Industrial Standards (JIS) as a dosimeter. The wavelength sensitivity of the photobleaching was compiled under monochromatic light radiation. Color changes in the specimens were measured in tristimuli values in color. by using a color analyzer. The aged pieces of paper were monitored continuously as they were photobleached under three different lighting conditions in a museum environment for $8000 \mathrm{~h}$. The combination of the yellowness index changes of the aged pieces of paper and the color changes of a blue wool reference was interpreted as follows. Photobleaching was governed by accumulated light intensities and was independant upon daily lighting conditions. The wavelength sensitivity of the photobleaching of aged paper showed that the maximum effect occurred at $420 \mathrm{~nm}$ in the visible light range. The blue wool reference was confirmed to perform well as a dosimeter.
\end{abstract}

Keywords: Traditional Japanese Paper;

Photobleaching; Wavelength Sensitivity;

Monochromatic Light; Visible Light; Blue Wool

Reference; Dosimeter

\section{INTRODUCTION}

Since ancient time, human has used many types of paper, each with its own history. However, the basic characteristics of all these papers may be considered to be derived from lignocellulosic materials [1]. Their du- rability with respect to photochemistry has been the subject of numerous studies [2]. However, further work is still required for a detailed understanding of photodegradation processes [3-5]. The materials from which paper is made consist of not a simple component but complicated compounds. Therefore, a comprehensive examination of this subject should be useful from the standpoint of natural sciences.

The paper containing lignin has a light-brown appearance. Lignin is a cross-linked racemic macromolecule with a molecular mass in excess of 10,000 u. It is relatively hydrophobic and aromatic in nature. The degree of polymerization in nature is difficult to measure as it is fragmented during extraction and its molecules consist of various substructures that appear to repeat themselves in a haphazard manner [6]. White paper is required for many end uses and therefore the paper containing lignin is chemically bleached [1]. Yellowing occurs as a result of thermal and photochemical reactions [7-9].

The natural phenomenon of photobleaching was observed in early times and used to whiten paper and textiles [10-14]. Sun-bleached paper found first mention in a compilation of recipes dating back to the 17th century, in which it was suggested that prints could be bleached by exposing them to sunlight while wet [11].

In this study, photobleaching of traditional Japanese paper was examined in a museum environment. Few studies have been conducted on the characteristics of the degradation of traditional Japanese paper. The specimen used in this study had already yellowed as a result of a slow but prolonged thermal reaction [10] caused by long-time storage for about 200 years.

This study consists of three experimental keypoints: First, continuous monitoring of the photobleaching of the specimen was conducted under different lighting levels in a museum for $8000 \mathrm{~h}$. Second, the light intensity was simultaneously monitored by using a blue wool reference as a dosimeter. Third, the above data were combined to interpret them consistently with a CIE colorchange scale. 
In addition, the wavelength sensitivity of the photobleaching of the specimen was investigated to characterize the nature of the photobleaching in comparison with previous studies with respect to protein-containing wool and silk substances [15-19].

The information collected in this study on the characteristics of color change in traditional Japanese paper in a museum environment will prove useful in the conservation of traditional cultural properties.

\section{EXPERIMENTAL}

\subsection{Materials}

\subsubsection{Traditional Japanese Paper}

The specimen used in this study was taken from an accounting ledger of about 300 pages. The date of 1809 , which was during the Edo Era of the Tokugawa Shogun, was written in India ink using a brush on the front cover. Thus, we assume that the paper was made about 200 years ago in Japan. The surface was thermally yellowed in color $(X=64.1, Y=67.6, Z=50.0$; yellowness index $=38.8, \mathrm{n}=7)$. The paper fiber was made of woodpaper mulberry, kozo, and mitsumata - which were traditional materials used to make paper during the Edo Era. The weight of the paper was $35.04 \mathrm{~g} / \mathrm{m}^{2}$.

\subsubsection{Use of Standard Dyed Cloth as Dosimeter}

A blue wool reference of the Japan Industrial Standards (JIS) [20] for evaluating colorfastness under daylight was used as a dosimeter to monitor light intensity in a museum [21]. The first grade standard was selected because it is the most fugitive, being dyed with C. I. Acid Blue 104 on a wool substrate. The blue wool standards consist of a set of wool samples that progressively and irreversibly fade when exposed to light. The specimens are loaded with different light-sensitive blue dyes so as to present different rates of fading. In principle, the JIS blue wool standard is similar to the ISO blue wool standard [22].

\subsection{Exposure to Light Sources}

\subsubsection{Polychromatic Light in a Museum}

The lighting conditions in three rooms - two exhibition rooms and a storage room - in a museum environment in Ishikawa Prefecture, Japan were examined in this study. The lighting was commonly provided by halogen lamps (Iwasaki, type JD110), which irradiate a stronger light under a given wattage and a whiter light compared to an ordinary light bulb with a tungsten filament. Exhibition room A was lit at the brightest level because details of the objects on display had to be clearly visible to visitors. The lighting in exhibition room B was kept at a lower level because the objects on display were more sensitive to deterioration under bright lighting conditions. The lights in the storage room were usually turned off other than when checking stored objects, which occurred rarely.

The exposure experiments were conducted through February 2, 2007 and January 17, 2008. Total exposure time was 8000 hours.

\subsubsection{Monochromatic Light in a Laboratory}

The samples were irradiated with monochromatic light by using a JASCO CRM-FD spectroirradiator (Figure 1). The spectroirradiator was equipped with a $300 \mathrm{~W} \mathrm{Xe}$ arc lamp with an elliptical half-sphere mirror to collect light emission. Radiation from this source was converted into monochromatic light by using a diffraction lattice grating with 1200 lines $/ \mathrm{mm}$. The wavelength dispersion was about $2 \mathrm{~nm} \cdot \mathrm{mm}^{-1}$ and the slit was set to $2 \mathrm{~mm}$, resulting in an accuracy of about $4 \mathrm{~nm}$ for each irradiation wavelength. The specimens were placed in an appropriate position in a sample holder and exposed to monochromatic radiations interspaced by about $16 \mathrm{~nm}$ within the $208-650 \mathrm{~nm}$ wavelength range. The light intensity in $\mathrm{W} / \mathrm{m}^{2} / \mathrm{nm}$ was periodically measured for each wavelength by using a photometer. The photometer was an advanced device that consisted of a thermopile detector attached to the spectroirradiator. Light exposures were carried out at temperatures and relative humidities ranging from $20^{\circ} \mathrm{C}$ to $25^{\circ} \mathrm{C}$ and from $50 \%$ to $70 \%$, respectively.

These systems were used in previous experiments published elsewhere $[23,24]$.

\subsubsection{Polychromatic Light in a Laboratory}

Specimens were also exposed to polychromatic light using an Atlas CI 35 xenon-arc Fade-O-meter, during which a radiant energy of $1.1 \mathrm{~W} / \mathrm{m}^{2} / \mathrm{nm}$ at $420 \mathrm{~nm}$ was

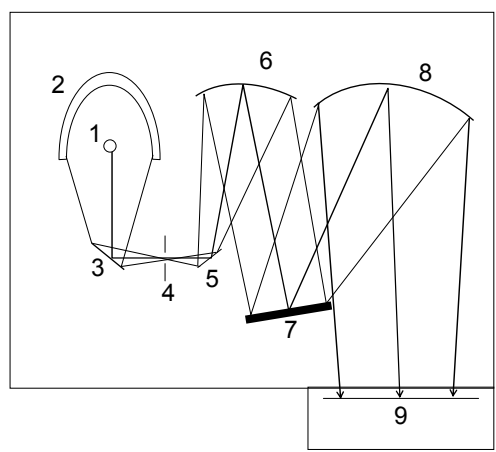

Figure 1. Schematic diagram of spectro-irradiator: 1: Xenon arc lamp; 2: Elliptical sphere mirror; 3: Mirror; 4: Slit; 5: Mirror; 6: Mirror; 7: Diffraction grating; 8: Mirror; 9: Sample holder. 
maintained.

\subsection{Evaluation of Fading Characteristics}

The specimen color change was measured using a Minolta Model CM-3700d color analyzer with a $4 \times 7$ $\mathrm{mm}^{2}$ viewing aperture. Color indices were expressed in $\mathrm{XYZ}$ and $\mathrm{L} * \mathrm{a} * \mathrm{~b} *$ systems.

The amount of fading was evaluated in terms of yellowness index and color difference as follows:

$$
\mathrm{YI}=(1.316 \mathrm{X}-1.164 \mathrm{Z}) / \mathrm{Y} \times 100
$$

where $\mathrm{X}, \mathrm{Y}$ and $\mathrm{Z}$ are tristimuli values in color.

And moreover, color difference was evaluated as follows:

$$
\Delta \mathrm{E}=\left[(\Delta \mathrm{L} *)^{2}+(\Delta \mathrm{a} *)^{2}+(\Delta \mathrm{b} *)^{2}\right]^{1 / 2},
$$

where $\Delta \mathrm{L}^{*}$ is the lightness-darkness difference, $\Delta \mathrm{a}^{*}$ is the redness-greenness difference, and $\Delta b^{*}$ is the yellowness-blueness difference.

\subsection{Determination of Radiant Wavelength Sensitivity}

The accumulated energy $\left(\mathrm{J} / \mathrm{m}^{2} / \mathrm{nm}\right)$ was calculated in light intensity $\left(\mathrm{W} / \mathrm{m}^{2} / \mathrm{nm}\right)$ by exposure time for each exposure wavelength, because the light source did not radiate at the same intensity at each wavelength. For a specimen, the relationship between the accumulated radiant energy and the yellowness index difference was examined in a time sequential experiment at each exposure wavelength. Then, a smooth curve was drawn to give a representative fading characteristic. Yellowness index difference data under a specified radiant energy was read out from the curve to obtain wavelength sensitivity characteristics at each exposure wavelength.

\section{RESULTS AND DISCUSSION}

\subsection{Color Change in Traditional Japanese Paper in a Museum Environment}

Figure 2 shows the photobleaching characteristics of traditional Japanese yellowed paper in a museum environment.

Before the discussion on photobleaching, we will present here a brief review on yellowness. The origin of the coloring materials in the paper containing lignin is lignin. The tendency of paper to yellow, called brightness reversion, occurs through the following two mechanisms: The first one is thermal, oxidative discoloration resulting from prolonged storage at ambient temperature. Thermal reversion is dependant upon temperature and humidity. The second one is photochemical,

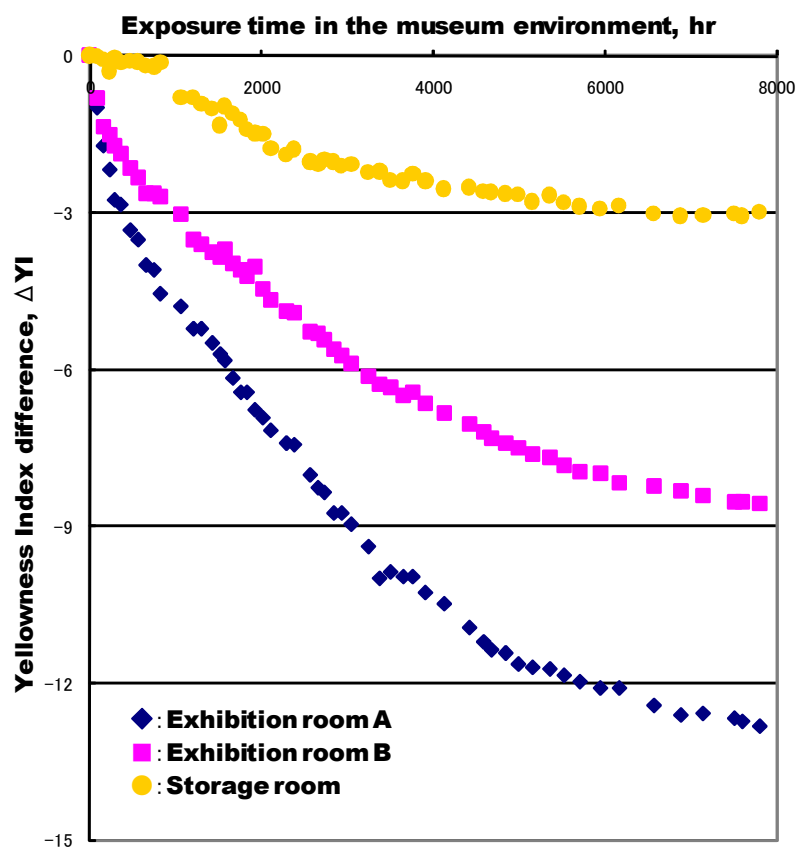

Figure 2. Photobleaching characteristics of traditional Japanese yellowed paper in a museum environment.

oxidative discoloration of paper through exposure to daylight. Photochemical reversion or light-induced yellowing of paper occurs within a short period [16]. It is considered that both thermal yellowing and light-induced yellowing are attributable to changes in ligninthe formation of complicated lignin derivatives - which are not easily identified [9]. Some aged paper may have chromophores, which result from the presence of lignin and also stem from the degradation of the cellulosic fraction [11].

As shown in Figure 2, thermally yellowed specimens were observed to be photobleached. The changing levels are indicated as a yellowness index difference. The yellowness decreased noticeably according to the exposure time in a museum environment. Moreover, the extent of yellowness change seems to depend upon the lighting conditions. In exhibition room A, where the light was the brightest, the degree of yellowness changed the most - to a yellowness index difference of about 13 after $8000 \mathrm{~h}$ of exposure. The next obvious change was observed in exhibition room $\mathrm{B}$, where the light was maintained at a lower level. There, the yellowness index difference was limited to about 7.5 after about $8000 \mathrm{~h}$ exposure. The minimum level was observed in the storage room, where the lights were usually off, at a yellowness index difference of about 3 for the duration of $8000 \mathrm{~h}$. In conclusion, the brighter the lighting conditions, the greater the extent of bleaching of the yellowed paper.

The above results partly support the experiments conducted by Annis and Reagan [10]. They examined 
the photobleaching effect on a specimen from a 19th century women's yellowed nightgown that was naturally aged cotton. The specimen was exposed to natural sunlight in Kansas, USA, between 10 a.m. and 2 p.m. during May and June for a total of $32 \mathrm{~h}$. Annis and Reagan concluded that the whiteness caused by hydrogen peroxide bleaching and that caused by sun bleaching were comparable. With respect to the fact that aged yellowness could be recovered, both our result and that of Annis and Reagan share a common recognition.

\subsection{Color Change in a Standard Dyed Specimen in a Museum Environment}

Figure 3 shows the fading characteristics of JIS blue wool first grade lightfastness in a museum environment. The light intensity in our study was expected to cause a color change in the dyed reference. Moreover, it was assumed that the same accumulated light intensity would cause the same color change, as shown as a color difference based on the $\mathrm{L}^{*} \mathrm{a}^{*} \mathrm{~b}^{*}$ system during $8000 \mathrm{~h}$ of exposure. As already discussed, rooms with three different lighting levels were used in this study.

The maximum distinguishable color change was observed to be about 11.5 of color difference in exhibition room A, where the lighting was the strongest. The second was observed to be about 7.0 of color difference in exhibition room $\mathrm{B}$. The third level was observed in the

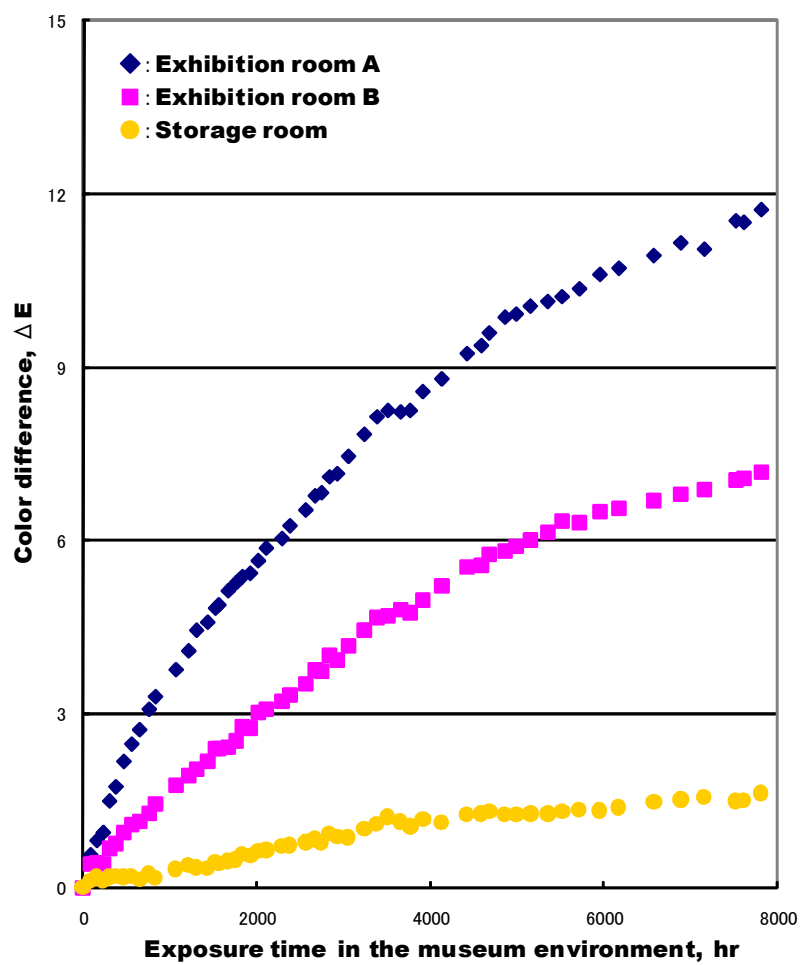

Figure 3. Fading characteristics of JIS blue wool first grade lightfastness standard in a museum environment. storage room at about 2.5 of color difference. The order of color change in the blue wool reference was similar to that observed with respect to the yellowness index difference change.

\subsection{Characteristics of Color Change in Traditional Japanese Paper with Respect to Dosimetry in a Museum Environment}

Figure 4 shows a comparison of the photobleaching characteristics of traditional Japanese yellowed paper and the fading characteristics of the JIS blue wool first grade lightfastness standard in the same museum environment. Figures $\mathbf{2}$ and $\mathbf{3}$ were combined into one figure through common exposure times in different rooms, as discussed above.

We obtained one cohesive line consisting of three different but overlapping lines observed under different lighting conditions. That is, the same color difference in the blue wool reference causes the same degree of photobleaching and yellowness index difference of an aged paper-irrespective of the lighting conditions. In fact, the role of the dosimeter was fulfilled by a blue wool reference in which color change occurred as expected.

In other words, it was verified that photobleaching was controlled in a regular manner by photoradiation. Thus, we submit a quantifying evidence that a lower

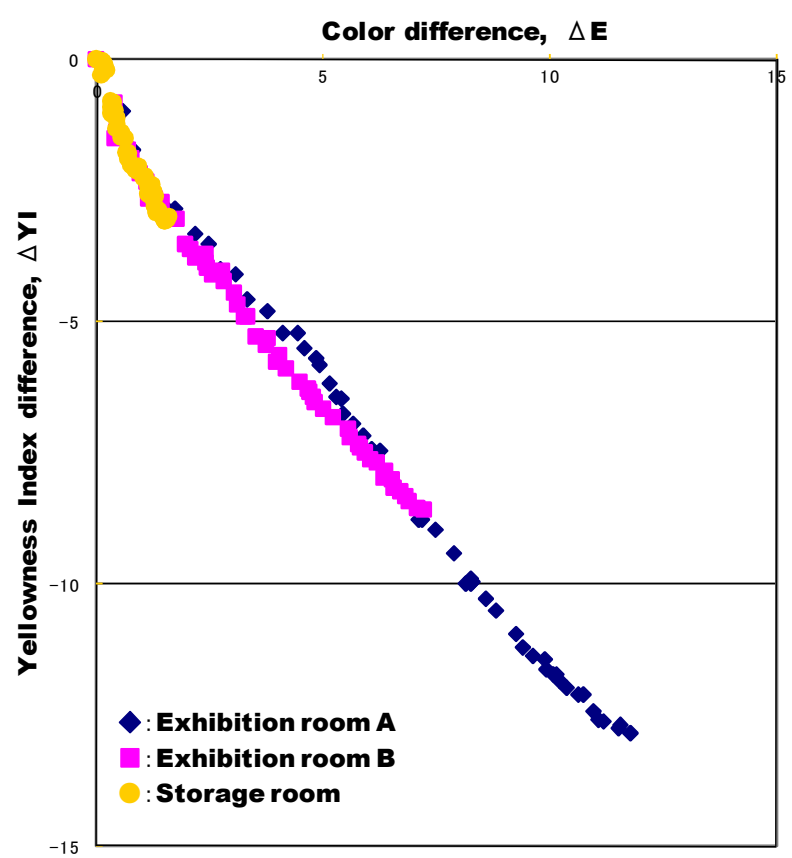

Figure 4. Comparison of photobleaching characteristics of traditional Japanese yellowed paper and fading characteristics of JIS blue wool first grade lightfastness standard in the same museum environment. 
accumulated light intensity causes less photodegradation in general.

\subsection{Reciprocal Relationship of Fading Characteristics of Blue Wool Reference}

In the discussion on the characteristics shown in Figure 4, we assumed latently that the blue wool reference would present the same color change - dependant solely on accumulated light intensity and not on spasmodic weak or strong light intensities - which is known as a reciprocal relationship. We examined this assumption in the experimental results shown in Figures 5 and 6.

First, the fading characteristics of the blue wool reference were examined as shown in Figure 5 under different radiation energies by using a fade-o-meter. Following three radiation conditions were set: $0.53,0.70$, and $0.90 \mathrm{~W} / \mathrm{m}^{2} / \mathrm{nm}$ at $420 \mathrm{~nm}$. Different curves of color difference were obtained for each radiation energy according to the exposure time.

Next, the actual exposure time of the fade-o-meter was converted into assumed exposure time in daylight intensity, which is reported as an example of a representative fine day [25]. This is shown in Figure 6, which shows a monotonous line that does not depend on the radiation energy levels of the fade-o-meter. We conclude that a reciprocal relationship is valid, albeit under limited radiation conditions.

\subsection{Wavelength Sensitivity Characteristics of Photobleaching of Traditional Japanese Yellowed Paper}

Figures 7(a) and (b) shows the fading characteristics of traditional Japanese yellowed paper under 310 and $420 \mathrm{~nm}$ wavelengths of monochromatic light irradiation, respectively. These wavelengths were selected as representative to concisely observe the overall fading characteristics. Each curve shows a variation in the yellowness of the specimen under a continuous monochromatic radiation at a constant wavelength. In this study, the yellowness changing characteristics of the paper were compiled when the accumulated radiant energy reached 5 $\mathrm{MJ} / \mathrm{m}^{2} / \mathrm{nm}$ for each wavelength. The final combined form of the characteristics, also known as an action spectrum [26,27], is shown in Figure 8. The photobleaching-causing peak ranged between 250 and $530 \mathrm{~nm}$, as shown in Figure 8. The maximum peak was observed at $420 \mathrm{~nm}$ in the visible light range. This suggests that ultraviolet A-rays (UVA) and visible light radiation have significant bleaching effects.

These experimental results of traditional Japanese yellowed paper are consistent with previous studies as

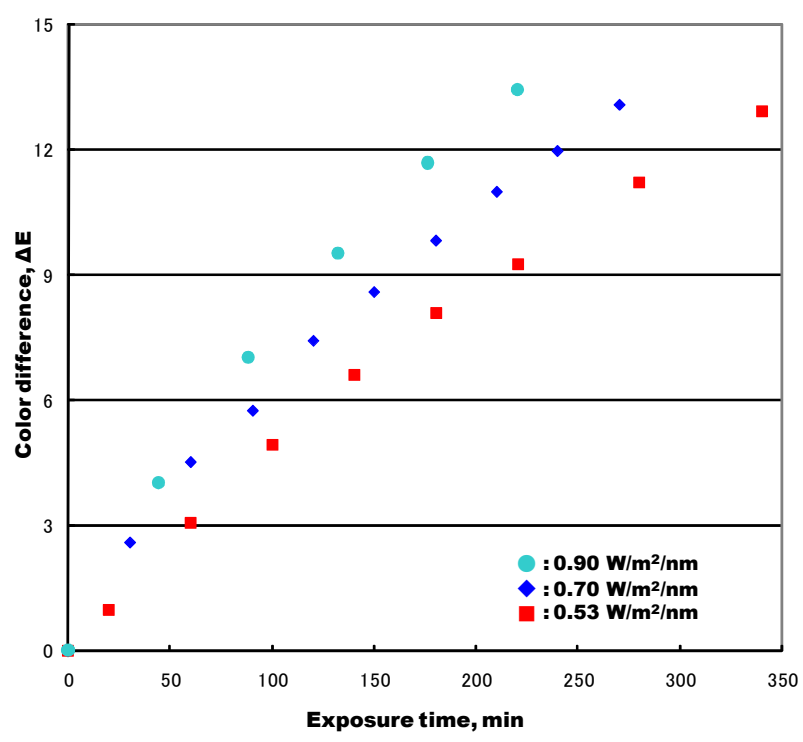

Figure 5. Fading characteristics of JIS blue wool first grade lightfastness standard, under energy intensities of $0.53 \mathrm{~W} / \mathrm{m}^{2} / \mathrm{nm}$, $0.70 \mathrm{~W} / \mathrm{m}^{2} / \mathrm{nm}$, and $0.90 \mathrm{~W} / \mathrm{m}^{2} / \mathrm{nm}$ at $420 \mathrm{~nm}$ determined using a fade-o-meter.

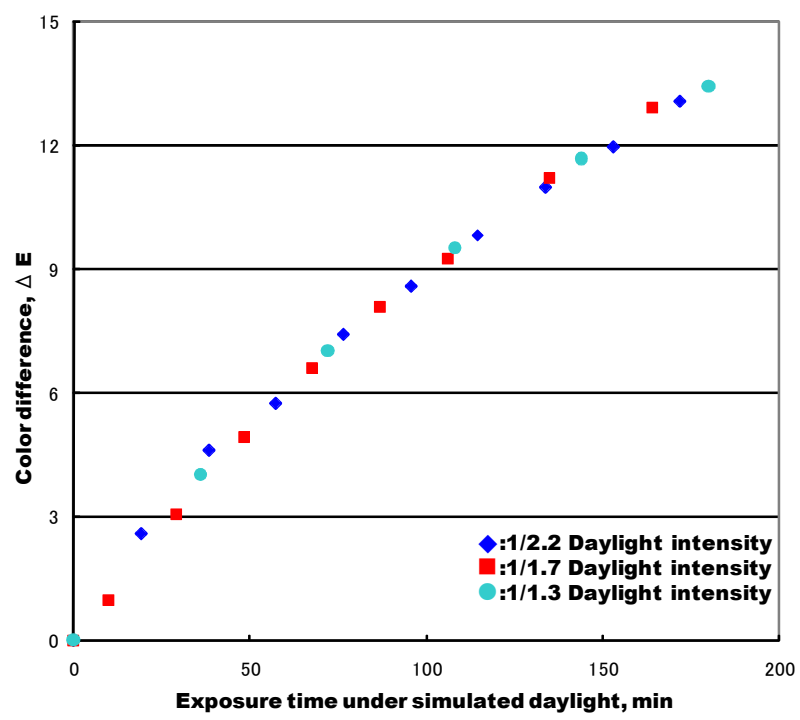

Figure 6. Fading characteristics of JIS blue wool first grade lightfastness standard under simulated daylight radiation.

follows:

The maximum effect of photobleaching of mechanical pulp paper was observed at 420 - $430 \mathrm{~nm}$, although considerable variations were found depending upon the tree species [17].

In the 1970s, light bleaching of aged paper saw a reemergence in the United States, and equipment was available on a commercial basis by the middle of the 1990s. Through methodological arguments, the effect of UV versus visible radiation was brought to the attention of researchers, leading to the recommendation that UV 

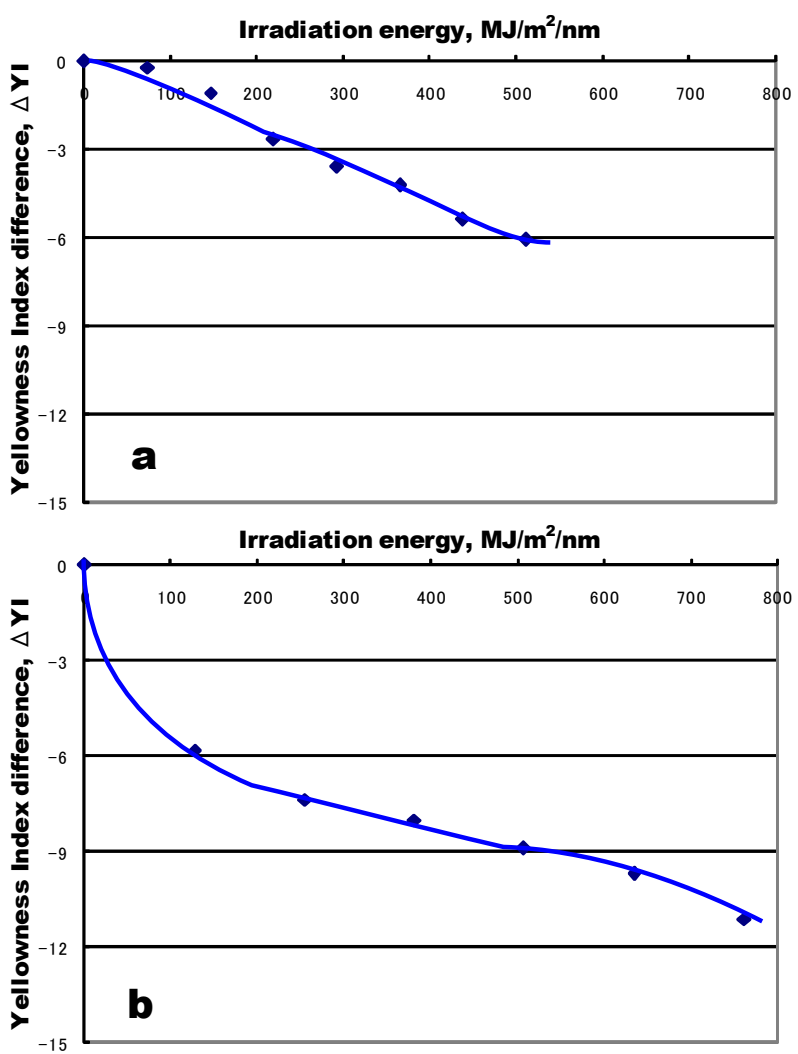

Figure 7. Photobleaching characteristics of traditional Japanese yellowed paper under (a) $310 \mathrm{~nm}$ and (b) $420 \mathrm{~nm}$ of monochromatic light irradiation.

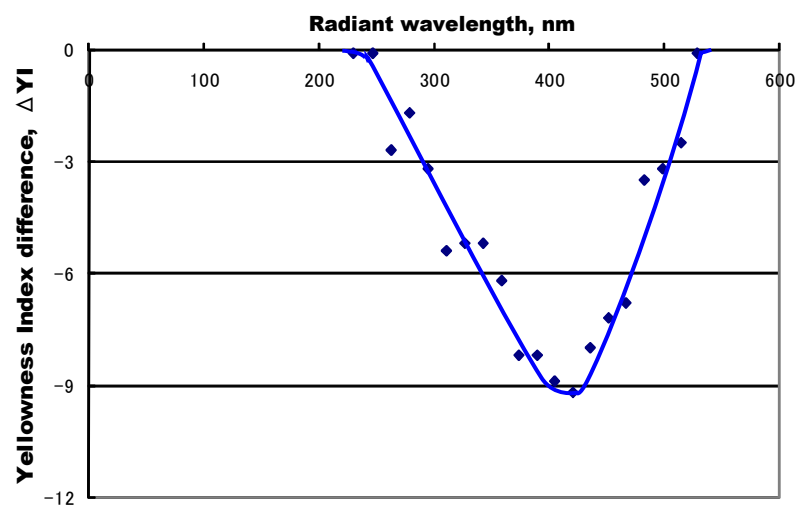

Figure 8. Wavelength sensitivity characteristics for photobleaching of traditional Japanese yellowed paper under 500 $\mathrm{kJ} / \mathrm{m}^{2} / \mathrm{nm}$ at each wavelength.

be eliminated from use in paper exposure to a light source [11]. This means that visible light is sufficiently effective in bleaching aged paper.

Another field of chemistry is the photoaging of proteins, which leads to photo yellowing. It is well known that blue-light radiation is effective in bleaching yellowed wool and silk fabrics [18,19].

Although the details of species derived from lignin derivatives or protein compounds have not been well characterized in terms of chemical structure analysis, exposure to light at a wavelength greater than $400 \mathrm{~nm}$ commonly destroys the long-wavelength emitting substances that are the origins of yellowing.

In this study, the chemical process of photobleaching of aged paper has not been discussed sufficiently. However, we provide an interpretation [11] as below: Sun bleaching of traditional textile and paper is related to the modern-day pulp-bleaching processes that employ oxygen, ozone, or hydrogen peroxide. These chemical agents work with the same species that, under solar radiation exposure, are produced in the presence of air and water. In the very minor quantities that are formed in this manner, they contribute to the bleaching effect. Although light bleaching of paper does not require the application of a chemical, it too is a chemical intervention.

\section{CONCLUSIONS}

In this study, the photobleaching characteristics of aged paper that was estimated to have been traditionally made during the Edo Era were examined from the viewpoints of radiation energy consistency and wavelength dependency.

The following results were obtained:

1) Yellowed specimens were observed to be photobleached according to the exposure time in a museum environment. The extent of yellowness change seemed to depend on the lighting intensities.

2) The combination of yellowness index changes and color changes in a blue wool reference showed that the yellowness index changes were controlled by accumulated light intensities and were not dependant upon lighting conditions, that is, brightness or darkness.

3) The use of the JIS blue wool reference as a dosimeter was found to be valid.

4) The wavelength sensitivity characteristics of the photobleaching of aged paper were compiled to show that the maximum effect was observed at $420 \mathrm{~nm}$ in the visible light range.

In conclusion, this study provides experimental evidence that a lower accumulated light intensity causes correspondingly less photobleaching with respect to aged Japanese paper.

\section{REFERENCES}

[1] Kennedy, J.F., Phillips, G.O. and Williams, P.A. (1989) Wood processing and utilization. Ellis Horwood Ltd., Chichester.

[2] Heitner, C. and Scaiano, J.C. (1993) Photochemical of lignocelluosic materials. ASC Symposium Series 531, New York.

[3] Earp, A.A., Rawling, T., Franklin, J.B. and Smith, G.B. 
(2010) Perylene dye photodegradation due to ketones and singlet oxygen. Dyes and Pigments, 84, 59-61.

doi:10.1016/j.dyepig.2009.06.012

[4] Sharratt, V., Hill, C.A.S., Zaihan J. and Kint, D.P.R. (2011) The influence of photodegradation and weathering on the water vapour sorption kinetic behaviour of scots pine earlywood and latewood. Polymer Degradation and Stability, 96, 1210-1218.

doi:10.1016/j.polymdegradstab.2011.04.016

[5] Caupos, E., Mazellier P. and Croue, J.-P. (2011) Photodegradation of estrone enhanced by dissolved organic matter under simulated sunlight. Water Research, 45, 3341-3350. doi:10.1016/j.watres.2011.03.047

[6] Wikipedia (2011) Lignin. http://en.wikipedia.org/wiki/Lignin

[7] Nolan, P., Van den Akker, J.A. and Wink, W.A. (1945) The fading of groundwood by light. Paper Trade Journal, 121, 33-37.

[8] Van den Akker, J.A., Lewis, H.F., Jones, G.W. and Buchanan, M.A. (1949) The nature of the color changes in groundwood. Tappi, 32, 187-192.

[9] Leary, G.J. (1967) The yellowing of wood by light. Tappi, 50, 17-19.

[10] Annis, Z.K. and Reagan B.M. (1979) Evaluation of selected bleaching treatments suitable for historic white cotton. Studies in Conservation, 24, 171-178. doi: $10.2307 / 1505779$

[11] Brückle, I. (2009) Bleaching in paper production versus conservation. Restaurator-International Journal for the Preservation of Library and Archival Material, 30, 280293.

[12] Suess, H.U. (2009) Bleaching. Restaurator-International Journal for the Preservation of Library and Archival Material, 30, 245-279.

[13] Brückle, I. (2009) Bleaching paper in conservation: Decision-making parameters. Restaurator-International Journal for the Preservation of Library and Archival Material, 30, 321-332.

[14] Henniges, U. and Potthast, A. (2009) Bleaching revisited: Impact of oxidative and reductive bleaching treatments on cellulose and paper. Restaurator-International Journal for the Preservation of Library and Archival Material, 30, 294-320.

[15] Oye, R. (1989) Degradation of bookpaper. In: Kennedy, J.F., Phillips, G.O. and Williams, P.A., Eds., Wood Processing and Utilization, Ellis Horwood Ltd., Chichester, 49.
[16] Heitner, H. (1993) Light-induced yellowing of woodcontaining papers. In: Heitner, C. and Scaiano, J.C. Eds., Photochemical of Lignocelluosic Materials, ASC Symposium Series 531, 1, 2-25.

[17] Forsskahl, I. and Tylli, H. (1993) Action spectra in the $\mathrm{UV}$ and visible region of light-induced changes of various refiner pulps. In: Heitner, C. and Scaiano, J.C. Eds., Photochemical of Lignocelluosic Materials, ASC Symposium Series 531, 3, 45-59.

[18] Takamura, E., Yoshizumi, K. and Crews, P.C. (2000) Photo yellowing and photo bleaching of silk and wool fabrics under monochromatic and multichromatic light radiation. The Textile Specialty Group Postprints, American Institute for Conservation of Historic \& Artistic Works, 515, 75-81.

[19] Zhang, H., Cookson, P. and Wang, X. (2009) Comparative study on accelerated weathering tests of wool fabrics. Textiles Research Journal, 78, 1004-1010. doi: $10.1177 / 0040517507087857$

[20] Japan Industrial Standard (1998) Test methods for color fastness to daylight. L 0841.

[21] Mignani, A.G., Bacci, M., Mencaglia, A.A. and Senesi, F. (2003) Equivalent light dosimetry in museums with blue wool standards and optical fibers. IEEE Sensors Journal, 3, 108-114. doi:10.1109/JSEN.2003.809439

[22] ISO (1980) Textiles-test for colour fastness daylight. 105-B01.

[23] Imaizumi, A. and Yoshizumi, K. (2006) Effect of substrates on action spectra of fading of a selected disperse dyestuff under light radiation. Textile Research Journal, 76, 757-764. doi:10.1177/0040517506070056

[24] Imaizumi, A. and Yoshizumi, K. (2006) Fading characteristics of a disperse dye on cellulose triacetate, polyester and nylon fabric substrates under monochromatic light radiation. Coloration Technology, 122, 86-92. doi:10.1111/j.1478-4408.2006.00014.x

[25] Japan Industrial Standard (1998) Secondary reference crystalline solar cells. C 9811.

[26] CIE (International Commission on Illumination) (1987) A reference action spectrum for ultraviolet induced erythema in human skin. International Commission on Illumination Journal, 6, 17-22.

[27] Andrady, A.L., Song, Y., Parthasarathy, V.R., Fuki, K. and Torikai, A. (1991) Photoyellowing of mechanical pulp, Part 1: Examination the wavelength sensitivity of light-induced yellowing using monochromatic radiation. Tappi Journal, 74, 162-168. 